Original Research Paper

\title{
Ethnobotanical Study of Sengkineh Cultural Tradition in Keruak District, East Lombok Regency
}

\author{
Sp. Ridha Titiani Fitri Al-idrus ${ }^{1 *}$, Sukiman ${ }^{1}$, Kurniasih Sukenti ${ }^{1}$ \\ ${ }^{1}$ Biology Study Program, Faculty of Mathematics and Natural Sciences, Mataram University, Jalan Majapahit 62 \\ Mataram, NTB, Indonesia
}

\section{Article History}

Received : August $16^{\text {th }}, 2021$

Revised : August $30^{\text {th }}, 2021$

Accepted : September $16^{\text {th }}, 2021$

Published : September $30^{\text {th }}, 2021$

*Corresponding Author:

Sp. Ridha Titiani Fitri Alidrus,

Biology Study Program, Faculty of Mathematics and Natural Sciences, Mataram University, Mataram, Indonesia;

Email: titinalidrus71@gmail.com
Abstract: Sengkineh is a seven-month cultural tradition since pregnancy, a coastal cultural tradition originating from Sulawesi that passed down from generation to generation. Three ethnic descendants carry out this tradition in the coastal area of Keruak District, namely Mandar, Bugis, and Bajo tribes. The rule consists of three rituals stages: throwing reinforcements into the sea, attaching a necklace to the stomach, and putting the bantang as a sign that they have followed or undergone the ritual. This tradition uses plant resources during its rituals. This study aims to determine the types of plants used in Sengkineh tradition in the Keruak District, East Lombok Regency, related to the plants used and the socio-cultural aspects of the tradition. It is hoped that the results of this research can become a reference for efforts to conserve natural and cultural resources, especially the types of plants used in Sengkineh tradition. This research is a descriptive exploratory survey that was conducted in August - September 2020 in Keruak District, East Lombok Regency. Data collection was carried out through interviews, participatory observation and documentation. Selection of respondents used purposive sampling and snowball sampling (non-discriminative snowball) methods. Data were analyzed descriptively and quantitatively, based on the calculation of Reported Use (RU) and Index of Cultural Significance (ICS). Based on the results obtained, 19 species of plants belong to 12 families and 17 genera used in Sengkineh tradition in Keruak District, East Lombok Regency. Plant species are dominated by Poaceae and Arecaceae which involves three species each. There are four use categories in Sengkineh tradition: offerings, ritual equipment, food ingredients, and secondary materials.

Keywords: Sengkineh tradition, Keruak District, Lombok Regency, Ethnobotany

\section{Pendahuluan}

Keragaman suku bangsa yang mendiami wilayah di Indonesia sebanding dengan banyaknya keragaman ritual adat yang terus dipertahankan kelestariannya oleh masing-masing suku yang terdapat di Indonesia. Pemanfaatan tumbuhan pada suku-suku bangsa di Indonesia cenderung mempunyai keragaman (Rahimah et al. 2018). Terdapat berbagai macam tumbuhan yang ada di lingkungan suku tertentu yang diolah atau dimanfaatkan langsung untuk keperluan bahan makanan, obat-obatan dan ritual-ritual adat
(Hasanuddin, 2018). Pada hakikatnya semua suku bangsa berupay untuk melestarikan dan mempertahankan kebudayaanya. Lingkungan budaya masyarakat tradisional kaya akan kearifan lokal, namun belum banyak diungkap bagaimana kearifan ini tumbuh dan terpelihara dalam kehidupan masyarakat tersebut.

Salah satu wilayah yang masih memegang teguh kearifan lokal adalah wilayah daerah pesisir pantai di Kecamatan Keruak Kabupaten Lombok Timur Nusa Tenggara Barat. Wilayah pesisir pantai di Kecamatan Keruak tersebut memiliki keunikan tersendiri dari segi bahasa, adat, 
khususnya tradisi. Tradisi yang masih kental dilakukan sampai saat ini salah satunya ialah tradisi Sengkineh. Tradisi Sengkineh merupakan tradisi tujuh bulanan sejak kehamilan, tradisi khas pesisir pantai yang berasal dari Sulawesi dan diwariskan secara turun temurun. Tradisi tersebut terdiri dari tiga tahapan ritual yakni membuang bala ke laut, ritual pemasangan kalung di perut, dan bantang sebagai tanda sudah mengikuti atau menjalani ritual.

Tradisi Sengkineh merupakan budaya Sulawesi yang dibawa oleh nenek moyang sejak dulu, mereka datang berlayar ke wilayah pesisir Kecamatan Keruak dan menetap di daerah tersebut dengan membawa berbagai macam tradisi yang dilakukan hingga saat ini. Tradisi Sengkineh dijalani oleh tiga suku yang berasal dari Sulawesi, yaitu Suku Mandar, Suku Bugis, dan Suku Bajo. Tradisi tersebut memanfaatkan jenis-jenis tumbuhan sebagai bahan penting untuk melakukan ritual. Saat ini belum ada penelitian terkait jenisjenis tumbuhan yang digunakan dalam tradisi Sengkineh yang mengkaji dari sisi etnobotani. Penelitian ini perlu dilakukan sebagai bentuk pelestarian tumbuhan dan pelestarian budaya di Indonesia.

\section{Bahan dan Metode}

\section{Prosedur penelitian}

Metode yang digunakan dalam penelitian ini yaitu: Observasi lapangan, wawancara, observasi partisipasif dan studi pustaka. Observasi lapangan dilakukan dengan menyurvei lokasi penelitian dan menemui tokoh masyarakat setempat. Selanjutnya pengumpulan data dilakukan dengan teknik wawancara,. Responden untuk wawancara ditentukan secara terpilih oleh peneliti (metode purposive) dan berdasarkan petunjuk informan kunci (metode snowball sampling). Responden yang dipilih antara lain sanro (dukun), belian (penyehat tradisional), tetua desa atau tokoh masyarakat dan warga. Wawancara dilakuakn melalui tanya jawab dalam bahasa Bajo menggunakan tipe pertanyaan open-ended dengan tetap mengikuti pedoman wawancara.

Observasi partisipatif dilakukan dengan cara mengikuti seluruh rangkaian acara mulai dari persiapan hingga selesai yang disertai pencatatanpencatatan dan dokumentasi menggunakan rekaman suara, foto dan video. Kajian literatur dilakuakn untuk mendapatkan data-data sekunder dan untuk kepentingan identifikasi tumbuhan.

Data-data yang dikumpulkan antara lain jenis-jenis tumbuhan yang digunakan dalam tradisi Sengkineh, pemanfaatan tumbuhan atau kegunaan tumbuhan dalam acara ritual, dan aspek sosial budaya meliputi makna filosofis dan nilai-nilai sosial budaya dari tradisi Sengkineh. Data jenis tumbuhan diperoleh melalui identifikasi. Jika terdapat jenis tumbuhan yang tidak diketahui nama ilmiahnya maka dibuat herbarium untuk diidentifikasi di laboratorium.

\section{Analisis data}

Data yang dianalisis dalam penelitian ini berupa data kualitatif dan data kuantitatif. Data kualitatif adalah data naratif atau deskriptif yang menjelaskan tentang suatu fenomena lewat koleksi intensif data-data melalui wawancara (Muhadjir, 1996). Data tersebut berupa jenis-jenis tumbuhan yang digunakan dalam tradisi Sengkineh, pemanfaatan tumbuhan, bagian organ tumbuhan yang digunakan, serta aspek sosial budaya yang terdapat pada tradisi Sengkineh. Data kuantitatif adalah data yang dapat diukur atau dihitung secara langsung, yang berupa informasi atau penjelasan yang dinyatakan dengan bilangan atau berbentuk angka (Sugiyono, 2010). Data kuantitatif pada penelitian ini disajikan dalam bentuk tabel dan grafik berdasarkan hasil perhitungan dengan menggunakan rumus Reported use value (RU), Index of Cultural Significance (ICS) (Turner, 1988 dalam Hoffman dan Gallaher, 2007).

Reported use value (RU) dihitung dengan rumus:

Keterangan:

$$
\boldsymbol{R U}=\sum_{i}^{n} \text { spesies }_{i}
$$

RU: Reported Use (Jumlah ragam pemanfaatan yang dilaporkan informan)

$\mathrm{n}$ : jumlah spesies

i: spesies ke-i

Index of Cultural Significance dihitung dengan rumus:

$$
I C S=\sum_{i=1}^{n}(q * i * e)
$$

Keterangan:

ICS: Index of Cultural Significant

q: nilai kualitas

i: nilai intensitas

e: nilai eksklusivitas

$n$ : jumlah ragam pemanfaatan 


\section{Hasil dan Pembahasan}

\section{Aspek Botani dalam Tradisi Sengkineh}

Penelitian dilakukan di dua desa yakni Desa Tanjung Luar dan Desa Ketapang Raya, Kecamatan Keruak, Kabupaten Lombok Timur.
Pada kedua desa tersebut, masyarakat masih melakukan tradisi Sengkineh. Terdapat berbagai macam tumbuhan yang digunakan dalam tradisi Sengkineh dan memiliki makna yang berbedabeda. Berikut ini adalah tabel jenis-jenis tumbuhan yang digunakan dalam tradisi Sengkineh (Tabel 1).

Tabel 1. Jenis-jenis tumbuhan yang berperan dalam tradisi Sengkineh

\begin{tabular}{|c|c|c|c|c|c|}
\hline \multirow[t]{2}{*}{ No } & \multicolumn{3}{|c|}{ Nama Spesies } & \multirow[t]{2}{*}{ Famili } & \multirow[t]{2}{*}{ Organ Tumbuhan } \\
\hline & Lokal & Indonesia & Ilmiah & & \\
\hline 1. & Pisah sabe & Pisang kepok & $\begin{array}{l}\text { Musa paradisiaca } \mathrm{L} \text {. } \\
\text { "kepok" }\end{array}$ & Musaceae & Buah, daun \\
\hline 2. & Pisah reje & Pisang raja & Musa paradisiaca L. "raja" & Musaceae & Buah \\
\hline 3. & Lekoq & Sirih & Piper betle L. & Piperaceae & Daun \\
\hline 4. & Saah & Merica & Piper nigrum $\mathrm{L}$. & Piperaceae & Biji \\
\hline 5. & Selokaq & Kelapa & Cocos nucifera $\mathrm{L}$. & Arecaceae & Buah, daun \\
\hline 6. & Buaq & Pinang & Areca catechu L. & Arecaceae & Buah \\
\hline 7. & Aren & Aren & $\begin{array}{l}\text { Arenga pinnata (Wurmb) } \\
\text { Merr. }\end{array}$ & Arecaceae & Getah batang \\
\hline 8. & Parai & Padi & Oryza sativa $\mathrm{L}$. & Poaceae & Buah \\
\hline 9. & Paripunuq & Ketan & Oryza sativa var.Glutinosa & Poaceae & Buah \\
\hline 10. & Tebu & Tebu & Saccharum officinarum L. & Poaceae & Batang \\
\hline 11. & Jagoh & Jagung & Zea mays L. & Poaceae & Kulit buah \\
\hline 12. & Bawah mire & $\begin{array}{l}\text { Bawang } \\
\text { merah }\end{array}$ & Allium cepa $\mathrm{L}$. & Liliaceae & Umbi \\
\hline 13. & Bawah pote & Bawang Putih & Allium sativum $\mathrm{L}$. & Liliaceae & Umbi \\
\hline 14. & Cabiq mire & Cabai merah & Capsicum annuum $\mathrm{L}$. & Solanaceae & Buah \\
\hline 15. & Tembako & Tembakau & Nicotiana tabacum L. & Solanaceae & Daun \\
\hline 16. & Kunyiq & Kunyit & Curcuma longa $\mathrm{L}$. & Zingiberaceae & Rimpang \\
\hline 17. & Warige & Widuri & Calotropis gigantea $\mathrm{L}$. & Apocynaceae & Batang \\
\hline 18. & Kemenyang & Kemenyan & Styrax benzoin D. & Styracaceae & Getah batang \\
\hline 19 & Ketumbah & Ketumbar & Coriandrum sativum $\mathrm{L}$. & Apiaceae & Biji \\
\hline 20. & Pele & Pala & Myristica fragrans $\mathrm{H}$. & Myristicaceae & Biji \\
\hline 21. & Tiboah & $\begin{array}{l}\text { Kacang } \\
\text { panjang }\end{array}$ & Vigna cylindrica $\mathrm{L}$. & Fabaceae & Biji \\
\hline
\end{tabular}

Berdasarkan hasil wawancara, delapan responden yang terdiri atas dua sanro (dukun), dua belian (penyehat tradisional), dua nelayan, dan dua ibu rumah tangga, diperoleh 21 jenis tumbuhan yang tergolong dalam 12 famili dan 17 genus yang digunakan dalam tradisi Sengkineh. (Tabel 1) menunjukkan jumlah spesies tumbuhan yang digunakan dalam tradisi Sengkineh yang diurutkan berdasarkan famili. Berikut ini adalah tabel persentase tumbuhan berdasarkan famili (Tabel 2). 
Tabel 2. Persentase tumbuhan berdasarkan famili

\begin{tabular}{lcc}
\hline Famili & $\begin{array}{c}\text { Jumlah } \\
\text { Spesies }\end{array}$ & $\begin{array}{c}\text { Persentase } \\
(\%)\end{array}$ \\
\hline Apiaceae & 1 & $8 \%$ \\
Apocynaceae & 1 & $8 \%$ \\
Arecaceae & 3 & $25 \%$ \\
Fabaceae & 1 & $8 \%$ \\
Liliaceae & 2 & $17 \%$ \\
Musaceae & 2 & $17 \%$ \\
Myristicaceae & 1 & $8 \%$ \\
Piperaceae & 2 & $17 \%$ \\
Poaceae & 3 & $25 \%$ \\
Solanaceae & 2 & $17 \%$ \\
Styracaceae & 1 & $8 \%$ \\
Zingiberaceae & 1 & $8 \%$ \\
\hline
\end{tabular}

Berdasarkan hasil pengamatan, jenis-jenis tumbuhan yang paling banyak dimanfaatkan dalam tradisi Sengkineh didominasi oleh famili Poaceae dan Arecaceae. Jumlah spesies tumbuhan Poaceae dan Arecaceae sebanyak tiga spesies yang memiliki persentase yang sama. Spesies tumbuhan pada famili Poaceae yakni Oryza sativa L., Oryza sativa var. glutinosa, Saccharum officinarum L., dan Zea mays L., dengan persentase sebesar $25 \%$. Spesies tumbuhan pada famili Arecaceae yakni Cocos nucifera L., Areca catechu L., Arenga pinnata L., dengan persentase sebesar $25 \%$. Beranekaragamnya jenis tumbuhan yang digunakan dalam upacara sengkineh menunjukkan arti penting keanekaragaman hayati dalam pelaksanaan tradisi budaya pada masyarakat peseisir Kecamatan Keruak.

Besarnya persentase famili Poaceae dan Arecaceae dibandingkan famili lain dikarenakan banyaknya pemanfaatan spesies tumbuhan yang digunakan masyarakat dalam kehidupan seharihari yakni sebagai bahan makanan, sebagai bahan penting dalam ritual Sengkineh dan ketersediannya masih melimpah di sawah, di kebun, dan di pasar. Berdasarkan organ tumbuhan yang digunakan dalam tradisi Sengkineh adalah batang, biji, buah, daun, getah batang, kulit buah, rimpang dan umbi (Tabel 3).

Tabel 3. Persentase jumlah organ tumbuhan

\begin{tabular}{lcc}
\hline $\begin{array}{c}\text { Nama organ } \\
\text { tumbuhan }\end{array}$ & $\begin{array}{c}\text { Jumlah organ } \\
\text { tumbuhan }\end{array}$ & Persentase (\%) \\
\hline Batang & 2 & $25 \%$ \\
Biji & 4 & $50 \%$ \\
Buah & 7 & $87 \%$
\end{tabular}

\begin{tabular}{lll} 
Daun & 4 & $50 \%$ \\
Getah batang & 2 & $25 \%$ \\
Kulit buah & 1 & $12 \%$ \\
Rimpang & 1 & $12 \%$ \\
Umbi & 2 & $25 \%$ \\
\hline
\end{tabular}

Organ tumbuhan yang paling banyak dimanfaatkan dalam tradisi Sengkineh yaitu buah dengan persentase sebesar $87 \%$, yang terdiri dari enam spesies tumbuhan, meliputi pisang kepok (Musa paradisiaca "kepok"), pisang raja (Musa paradisiaca "raja"), kelapa (Cocos nucifera L), pinang (Areca catechu L), padi (Oryza sativa L), ketan (Oryza sativa var. glutinosa), Capsicum annuит L. Hal ini dikarenakan buah merupakan organ tumbuhan yang paling banyak pemanfaatannya dalam tradisi Sengkineh khususnya sebagai bahan sesaji, perlengkapan ritual, dan bahan pangan. Tumbuhan dalam tradisi Sengkineh terdiri atas tanaman budidaya dan non budidaya. Sanro (dukun) dan sebagian masyarakat di wilayah pesisir pantai kecamatan Keruak dapat mengenali dengan baik jenis tumbuhan yang digunakan dalam tradisi Sengkineh.

\section{Nilai Penting Jenis-jenis Tumbuhan Berdasarkan ICS}

Tabel 4. Nilai penting jenis-jenis tumbuhan berdasarkan ICS

\begin{tabular}{|c|c|c|c|c|c|c|c|}
\hline \multirow[t]{2}{*}{ No } & \multirow[t]{2}{*}{ Nama Tumbuhan } & \multicolumn{4}{|c|}{ Ragam Pemanfaatan } & \multirow{2}{*}{$\begin{array}{l}\mathrm{R} \\
\mathrm{U}\end{array}$} & \multirow{2}{*}{$\begin{array}{l}\sum_{\mathrm{ICS}} \\
\mathrm{IC}\end{array}$} \\
\hline & & A & B & $\mathrm{C}$ & $\mathrm{D}$ & & \\
\hline 1. & $\begin{array}{l}\text { Musa paradisiaca } \\
\text { "kepok" }\end{array}$ & 20 & 20 & 0 & 30 & 3 & 70 \\
\hline 2. & $\begin{array}{l}\text { Musa paradisiaca } \\
\text { "raja" }\end{array}$ & 16 & 8 & 0 & 0 & 2 & 24 \\
\hline 3. & Piper betle L. & 20 & 20 & 0 & 30 & 3 & 70 \\
\hline 4. & Piper nigrum L. & 0 & 0 & 6 & 0 & 1 & 6 \\
\hline 5. & Cocos nucifera L. & 16 & 20 & 20 & 24 & 4 & 80 \\
\hline 6. & Areca catechu L. & 0 & 16 & 0 & 0 & 1 & 16 \\
\hline 7. & $\begin{array}{l}\text { Arenga pinnata } \\
\text { (Wurmb) Merr. }\end{array}$ & 0 & 0 & 10 & 0 & 1 & 10 \\
\hline 8. & Oryza sativa $\mathrm{L}$. & 20 & 16 & 20 & 0 & 3 & 56 \\
\hline 9. & $\begin{array}{l}\text { Oryza sativa } \\
\text { var.glutinosa }\end{array}$ & 0 & 0 & 6 & 0 & 1 & 6 \\
\hline 10. & $\begin{array}{l}\text { Saccharum } \\
\text { officinarum L. }\end{array}$ & 16 & 0 & 0 & 0 & 1 & 16 \\
\hline 11. & Zea mays L. & 16 & 0 & 0 & 24 & 2 & 40 \\
\hline 12. & Allium cepa L. & 0 & 0 & 6 & 0 & 1 & 6 \\
\hline
\end{tabular}




\begin{tabular}{|c|c|c|c|c|c|c|c|}
\hline 13. & Allium sativum $\mathrm{L}$. & 0 & 0 & 6 & 0 & 1 & 6 \\
\hline 14. & $\begin{array}{l}\text { Capsicum aпnиит } \\
\text { L. }\end{array}$ & 0 & 0 & 6 & 0 & 1 & 6 \\
\hline 15. & $\begin{array}{l}\text { Nicotiana tabacum } \\
\text { L. }\end{array}$ & 20 & 0 & 0 & 0 & 1 & 20 \\
\hline 16. & Curcuma longa $\mathrm{L}$. & 20 & 16 & 8 & 0 & 3 & 44 \\
\hline 17 & $\begin{array}{l}\text { Calotropis gigantea } \\
\text { L. }\end{array}$ & 0 & 6 & 0 & 0 & 1 & 6 \\
\hline 18. & $\begin{array}{l}\text { Styrax benzoin } \\
\text { Dryand. }\end{array}$ & 0 & 20 & 0 & 0 & 1 & 20 \\
\hline 19. & $\begin{array}{l}\text { Coriandrum sativum } \\
\text { L. }\end{array}$ & 0 & 0 & 6 & 0 & 1 & 6 \\
\hline 20. & $\begin{array}{l}\text { Myristica fragrans } \\
\text { Houtt. }\end{array}$ & 0 & 0 & 6 & 0 & 1 & 6 \\
\hline 21. & Vigna cylindrica $\mathrm{L}$. & 0 & 0 & 6 & 0 & 1 & 6 \\
\hline
\end{tabular}

Berdasarkan hasil perhitungan Index of Cultural Significance (ICS), terdapat lima tumbuhan dengan nilai ICS tertinggi yaitu, Cocos nucifera sebesar 80, Piper betle sebesar 70, Musa paridisiaca "kepok" sebesar 70, Oryza sativa sebesar 56, dan Curcuma longa sebesar 44. Spesies tersebut memiliki nilai ICS yang lebih tinggi dari tumbuhan lain karena intensitas penggunaannya yang sangat tinggi, yaitu digunakan pada hampir semua jenis perlengkapan ritual Sengkineh dan sebagai bahan pangan dalam tradisi Sengkineh, serta menjadi komponen utama yang sangat berperan dan tidak dapat diganti dengan spesies lain. Sedangkan spesies yang termasuk dalam kategori nilai ICS terendah sebesar enam yaitu Piper nigrum, Oryza sativa var. glutinosa., Allium cepa., Capsicum annuum, Calotropis gigantea, Coriandrum sativum, Myristica fragrans, dan Vigna cylindrica. Hal ini terjadi karena nilai intensitas penggunaannya jarang atau minimal, serta hanya sebagai bahan pangan yang dijadikan sebagai bingkisan dalam tradisi Sengkineh dan sebagai pemenuh kebutuhan sekunder.

\section{Pemanfaatan tumbuhan dalam tradisi Sengkineh di Kecamatan Keruak}

Berdasarkan hasil perhitungan Reported Use (RU) yaitu jumlah ragam pemanfaatan yang dilaporkan oleh narasumber di dua desa wilayah pesisir pantai Kecamatan Keruak, terdapat empat jumlah ragam pemanfaatan yakni sebagai sesaji, perlengkapan ritual, bahan pangan yang dijadikan sebagai bingkisan, dan bahan materi sekunder.
Sesaji

Pada ritual Sengkineh terdapat sesaji dari berbagai macam tumbuhan yang wajib ada pada ritual Sengkineh. Berikut ini adalah jenis-jenis tumbuhan yang digunakan sebagai sesaji dalam tradisi Sengkineh (Gambar 1).

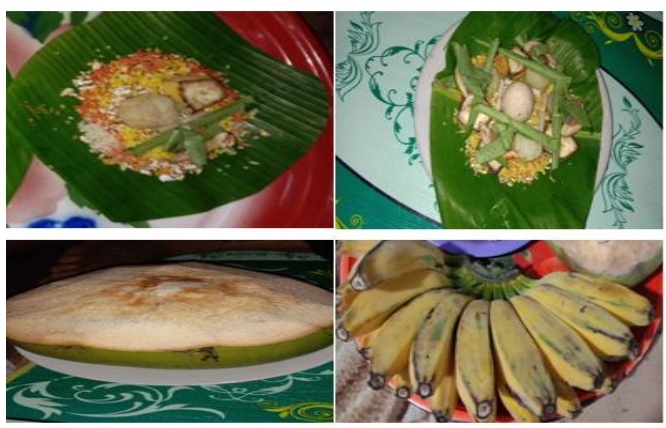

Gambar 1. Jenis-jenis tumbuhan yang digunakan sebagai sesaji

Tumbuhan yang digunakan sebagai sesaji dalam tradisi Sengkineh terdiri dari tujuh spesies tumbuhan yakni, pisang kepok Musa paradisiaca "kepok" (daun, buah), pisang raja Musa paradisiaca "raja" (buah), kelapa Cocos nucifera (daun, buah), sirih Piper betle (daun), jagung Zea mays (kulit buah), tembakau Nicotiana tabacum (daun), tebu Saccharum officinarum (batang), dan padi disangrai dan beras empat warna Oryza sativa (buah), warna pada beras terdiri warna merah, warna kuning, warna hitam dan warna putih. Pewarnaan tersebut dilakukan secara tradisional menggunakan bahan dasar dari tumbuhan, seperti beras warna kuning ditambahkan pewarna kunyit Curcuma longa (rimpang), beras bewarna merah menggunakan perasan kunyit yang ditambahkan dengan sedikit kapur sehingga menimbulkan warna merah, dan beras berwarna hitam menggunakan arang, sedangkan beras berwarna putih tidak menggunakan pewarna apapun. Penggunaan sesaji dengan tujuh spesies tumbuhan dalam tradisi Sengkineh agar mencapai rukun dalam tradisi tersebut dan jenis-jenis tumbuhan yang digunakan memiliki makna atau simbol berbeda-beda.

Beras berwarna putih melambangkan tulang putih bersih, beras berwarna merah melambangkan darah, beras berwarna kuning melambangkan uraturat nadi dan beras berwarna hitam melambangkan tanah karena manusia berasal dari tanah dan akan kembali ke tanah. Empok-empok/padi (Oryza sativa) sangat erat hubungannya dengan manusia 
karena merupakan bahan pokok yang diartikan sebagai sumber kehidupan. Tebu (Saccharum officinarum) mempunyai cita rasa manis dan sebagai penambah energi, masyarakat awam mengatakan bahwa pemberian tebu pada sesaji dapat memberikan dampak positif untuk proses persalinan.

Pada komponen sesaji terdapat rokok sesaji yang menggunakan kulit jagung (Zea mays), tembakau (Nicotiana tabacum), dan diikat dengan sirih (Piper betle). Rokok tersebut bermakna penghormatan terhadap nenek moyang karena rokok tersebut ada pada zaman dahulu. Pisang (Musa paridisiaca L. "kepok") memiliki keistimewaan yaitu pohonnya tidak akan mati sebelum berbuah dan memiliki banyak manfaat. Pisang kepok merupakan bagian penting dalam melakukan ritual Sengkineh. Pada sesaji pisang kepok digunakan untuk Suku Bugis dan Suku Bajo. Penggunaan pisang kepok pada sesaji bermakna harapan agar dapat memudahkan fase bersalin. Berbeda halnya dengan pisang raja (Musa paridisiaca L. "raja"). Pisang raja hanya digunakan untuk keturunan Suku Mandar tidak untuk Suku Bugis, dan Suku Bajo. Menurut masyarakat awam Suku Mandar dikenal bangsawan yang lebih tinggi sehingga pisang yang digunakan untuk sesaji dan perlengkapan ritual menggunakan pisang istimewa yaitu pisang raja.

Pada tradisi Sengkineh terdapat tiga sesaji yang diletakkan pada tempat berbeda yaitu di depan pintu, di dapur, dan dibuang ke laut. Sesaji memiliki makna yang berbeda-beda. Sesaji yang diletakkan di depan pintu memiliki makna agar ibu dan anak di dalam kandungan dijauhkan dari halhal yang tidak diinginkan, sesaji yang diletakkan di dapur memiliki makna agar bayi yang ada di dalam kandungan memberikan dampak positif bagi ibu yang mengandungnya dan semua keluarganya, kemudian sesaji yang dibuang ke laut memiliki makna bahwa membuang bala' berupa sesaji tersebut dapat menangkal pengaruh buruk dari daya kekutan gaib yang tidak dikehendaki dan menjauhkan hal-hal yang tidak diinginkan pada saat melahirkan. Berbeda halnya dengan penelitian Markhomah (2019) di Desa Blengorkulon Kabupaten Kabumen, sesaji (sajen) digunakan pada tradisi pernikahan, sajen diletatakkan pada tiga belas tempat seperti di dapur, tempat penyimpanan beras, sumur, sawah, dan tempat lainnya, dan dilakukan tujuh hari sebelum hari sakral berlangsung. Masyarakat Desa
Blengorkulon memaknai ritual sajen sebagai bentuk selamatan atau tasyakuran untuk menyedekahkan sebagian yang dimiliki kepada makhluk Allah yang lainnya baik yang terlihat maupun yang gaib.

\section{Perlengkapan ritual}

Perlengkapan ritual merupakan segala perlengkapan yang digunakan saat ritual Sengkineh berlangsung. Berikut ini adalah dokumentasi ritual Sengkineh dan perlengkapan ritual yang digunakan dalam tradisi Sengkineh (Gambar 2).

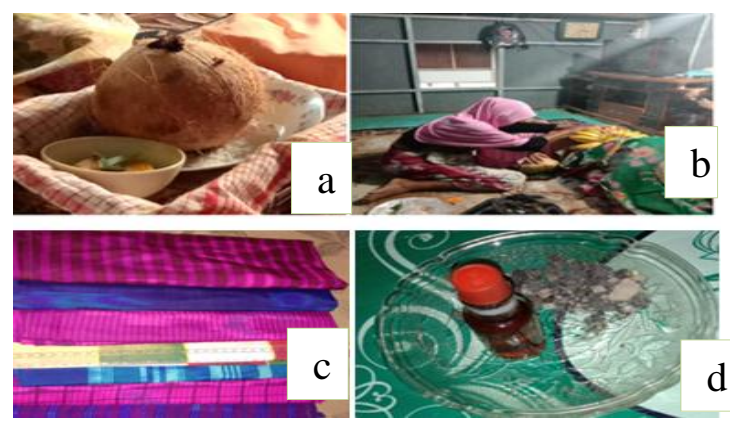

Gambar 2. Perlengkapan ritual yang digunakan dalam tradisi Sengkineh. Keterangan: a. Komponen bantang dan sembe', b. Ritual sebelum pemasangan kalung di perut (sambang), c. kain sabbe, d. Kemenyan dan minyak wangi khusus ritual.

Tumbuhan yang digunakan sebagai perlengkapan ritual Sengkineh terdiri dari delapan spesies tumbuhan yakni pisang kepok (Musa paradisiaca "kepok") yang biasa digunakan bagi Suku Bugis dan Suku Bajo, pisang raja (Musa paradisiaca "raja") yang biasa digunakan bagi Suku Mandar, kelapa tua (Cocos nucifera) dan beras (Oryza sativa), yang digunakan pada saat akan berakhirnya ritual Sengkineh dengan memercikan air kelapa dan beras kepada semua para tamu undangan yang telah hadir pada saat ritual berlangsung. Kemudian, sirih (Piper betle) dan pinang (Areca catechu) digunakan untuk membuat sembe' (tanda). Selanjutnya, kunyit (Curcuma longa) digunakan sebagai pewarna bahan bantang dimana bahan utama bantang ialah beras (Oryza sativa) yang dihaluskan. Kemudian serat batang widuri (Caloptropis gigantea) yang dimanfaatkan untuk membuat tali sambang (kalung perut) dan kemenyan (Styrax benzoin).

Kemenyan (Styrax benzoin) sangat penting dalam tradisi Sengkineh karena pada saat ritual 
berlangsung harus dilakukan pembakaran kemenyan (dupa) yang selalu dipadukan dengan minyak wangi khas ritual, dua komponen tersebut wajib ada pada saat ritual berlangsung. Tumbuhan yang digunakan untuk membuat minyak wangi ritual ialah kelapa (Cocos nucifera) dan kemenyan (Styrax benzoin). Fungsi bakar kemenyan ialah sebagai pengiring doa dalam melakukan tradisi Sengkineh dan memberikan ketenangan bagi ibu hamil karena memiliki senyawa aromatik. Menurut Jayusman, (2014) kemenyan mengandung asam sinamat yang digunakan sebagai antiseptic, expectorant (pelega pernafasan), obat katarak mata dan pada pembuatan antibiotic streptomycin. Menurut Solikhin (2010) menyatakan bahwa, pembakaran kemenyan dalam ritual mistik sebagian kaum muslim Jawa, bukanlah laku yang musyrik. Pada zaman Nabi Ibrahim AS. juga sudah ada kebiasaan membakar kemenyan. Untuk zaman Nabi Muhammad SAW, pembakaran kemenyan sering diganti dengan menggunakan bau-bau yang harum yang dinyatakan sebagai "di sukai Allah", baik kemenyan maupun wangi-wangian.

Penggunaan jenis-jenis tumbuhan pada perlengkapan ritul Sengkineh adalah untuk mencapai rukun dalam tradisi Sengkineh dan merupakan suatu kearifan lokal (lokal wisdom) yang diwariskan secara turun temurun dari satu generasi ke generasi. Pengetahuan tradisional (traditional knowlegde) termasuk dalam lingkup karya intelektual yang bersumber dari ide, gagasan atau penemuan kelompok masyarakat suatu negara dan merupakan karya intelektual bangsa Indonesia yang telah ada sejak zaman nenek moyang dan dikembangkan serta dipelihara secara turun temurun (Rongiyati, 2011). Secara umum kearifan lokal dipahami sebagai gagasan-gagasan setempat yang bersifat bijaksana, penuh kearifan dan bernilai baik yang tertanam dan diikuti oleh anggota masyarakatnya (Hasanah, 2016). Meskipun kearifan tersebut bernilai lokal, namun nilai yang terkandung di dalamnya bersifat universal dan diterima oleh masyarakat (Sartini, 2009).

Selain tumbuhan, perlengkapan ritual yang harus ada pada saat ritual Sengkineh yaitu kain Sabbe, yaitu kain khas Suku Bugis Sulawesi Selatan yang terbuat dari kain sutra. Kain sabbe digunakan oleh ibu hamil yang melakukan Sengkineh sebagai simbol warisan budaya nenek moyang yang berasal dari Sulawesi.

\section{Bahan pangan}

Pada tradisi Sengkineh terdapat berbagai makanan khas yang digunakan sebagai bingkisan karena untuk melakukan Sengkineh harus mengundang sanak, keluarga, tetangga dekat maupun jauh dan merupakan ajang silaturrahmi bersama keluarga yang merupakan nilai sosial budaya dalam tradisi Sengkineh. Berikut ini adalah beberapa hidangan yang digunakan sebagai bingkisan (Gambar 3):

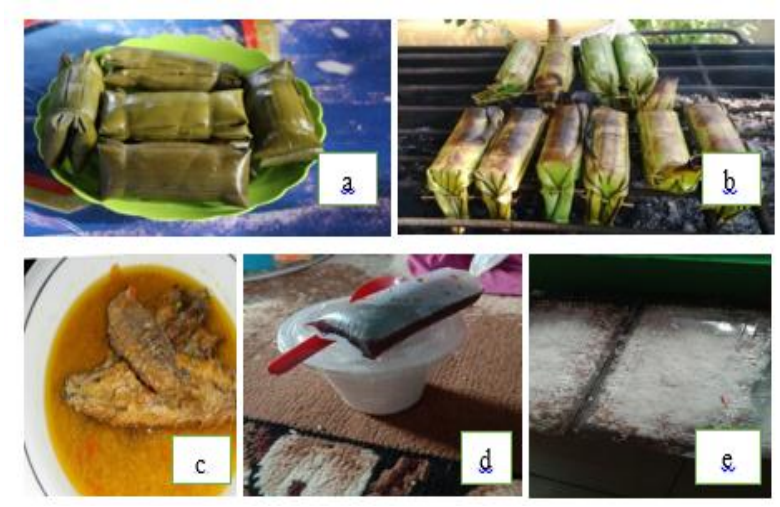

Gambar 3. Makanan yang digunakan sebagai bingkisan. Keterangan: a. Buras, b. Gogos, c. Palumara ikan tongkol, d. Bubur putih, e. Songkol.

Terdapat berbagai macam makanan untuk dijadikan sebagai bingkisan dalam tradisi Sengkineh yang merupakan makanan khas Indonesia khususnya makanan khas pesisir pantai asal Sulawesi. Makanan tersebut yaitu buras, gogos, palumara ikan tongkol, dan songkol. Buras yang berbahan dasar beras (Oryza sativa), kelapa (Cocos nucifera) dan bahan tambahan yakni biji kacang panjang (Vigna cylindrica), gogos berbahan dasar ketan (Oryza sativa var. glutinosa dan kelapa (Cocos nucifera). Bingkisan Buras dan gogos dijadikan sebagai olahan pengganti nasi yang dibungkus dengan daun pisang karena terbilang lebih praktis dan lebih memiliki cita rasa yang khas. Pemanfaatan bahan alami seperti daun sebagai pembungkus makanan memberikan dampak positif bagi lingkungan dan konsumen karena merupakan bahan yang tidak mengandung bahan kimia berbahaya atau beracun, mudah ditemukan, mudah dilipat dan memberi aroma sedap pada makanan (Astuti, 2009).

Hidangan lain adalah palumara ikan tongkol, bahan utamanya ialah ikan tongkol, sebagaimana masyarakat pesisir di Kecamatan Keruak menyebutnya dengan sebutan dayah 
tongkol (ikan tongkol) yang biasa digunakan sebagai bahan olahan baik itu dalam acara tradisi, dan sebagai makanan sehari-hari, karena memiliki cita rasa gurih dan nikmat. Bahan-bahan lain yang digunakan sebagai bumbu palumara ikan tongkol yakni kelapa (Cocos nucifera), merica (Piper nigrum), bawang merah (Allium cepa), bawang putih (Allium sativum), cabai rawit merah (Capsicum annuum), kunyit (Curcuma longa), ketumbar (Coriandrum sativum), dan pala (Myristica fragrans). Jenis-jenis tumbuhan tersebut juga dapat ditemukan di lingkungan masyarakat Sukolilo yang biasa digunakan sebagai bahan bumbu dan aroma masakan, terutama dari suku Zingiberaceae seperti jahe (Zingiber offcinale), lengkuas (Alpinnia galanga), kunyit (Curcuma domestica), kunci (Kaempfera angustifolia), dan kencur (Kaempferia galanga) (Irsyad et al, 2013).

Bingkisan yang kerap kali digunakan dalam tradisi Sengkineh juga yaitu bubur putih yang merupakan makanan khas Indonesia. Bahan dasar bubur putih yakni beras (Oryza sativa) yang tidak dijadikan tepung, kelapa (Cocos nucifera) dan ditambahkan gula aren (Arenga pinnata) sebagai bahan pemanis dan yang terakhir ialah songkol berbahan dasar ketan (Oryza sativa var. glutinosa dan kelapa (Cocos nucifera). Bingkisan bubur putih tersebut mengalami peralihan, yang semula harus menggunakan piring berwarna putih sebagai wadah bingkisan menjadi plastik. Hal ini dikarenakan masyarakat pesisir pantai Kecamatan Keruak memilih pembungkus makanan yang lebih praktis.

Buras, gogos, dan pelalah ikan tongkol dijadikan satu sebagai bingkisan. Sementara itu, bubur putih dan songkol tidak dijadikan satu bingkisan. Bingkisan semacam ini juga terdapat pada upacara adat kelahiran di Sukoharjo, dimana tumbuhan yang digunakan antara lain bubur sumsum untuk ngebor-ngebori, bunga setaman yang digunakan untuk siraman, dan sayuran yang digunakan untuk nasi urap, diperoleh dengan cara membeli di pasar (Liina, 2017).

\section{Bahan materi sekunder}

Bahan materi sekunder merupakan bahan tambahan yang digunakan dalam tradisi Sengkineh. Berikut ini adalah tumbuhan yang digunakan sebagai bahan materi sekunder dalam tradisi Sengkineh (Gambar 4).

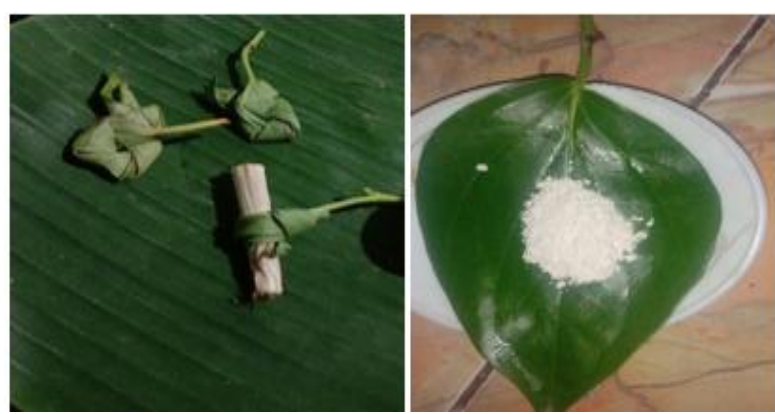

Gambar 4. Tumbuhan yang digunakan sebagai bahan materi sekunder

Tumbuhan yang digunakan sebagai bahan materi sekunder dalam tradisi Sengkineh di antaranya adalah sirih (Piper betle) yang dimanfaatkan sebagai alas sembe' (tanda) dan untuk mengikat rokok, kelapa (Cocos nucifera) dimanfatatkan tulang daunnya sebagai semat pembuatan gogos, jagung (Zea mays) dimanfaatkan kulit buah jagung yang dijadikan sebagai pembungkus rokok. Pisang (Musa paradisiaca) dimanfaatkan daunnya untuk dijadikan alas dan pembungkus makanan, yakni gogos dan buras. Penggunaan daun sebagai pembungkus makanan merupakan bahan kemasan yang paling aman digunakan untuk manusia dan lingkungan serta bisa menjadi pembungkus yang mempunyai ciri khas dan menjadi produk potensial untuk dikembangkan secara ekonomis (Widodo 2003 dalam Astuti 2009). Penggunaan bahan alami tersebut merupakan pengetahuan tradisional yang sangat berharga dan merupakan kekayaan budaya yang perlu digali untuk dilestarikan dan dikembangkan agar pengetahuan tersebut tidak hilang (Rini, 2017).

Nilai filosofis atau makna simbolik yang terkandung dalam setiap tumbuhan yang dipakai dalam prosesi upacara adat istiadat merupakan hal yang tidak bisa dijelaskan secara ilmiah maknanya. Semua makna yang terkandung pada setiap tumbuhan adalah harapan baik bagi orang yang melangsungkan acara adat tersebut (Rahimah et al. 2018). Begitu juga dalam tradisi sengkineh, setiap tumbuhan yang digunakan mempunyai makna filosofis sebagai simbol harapan dan doa untuk kebaikan dan keselamatan ibu dan bayi dalam kandungannya.

Ritual adat terkait kelahiran bayi dilakukan oleh beberapa suku bangsa di Indonesia. Masingmasing suku memperlihatkan cara yang berbeda dalam melaksanakan ritual adat tersebut. Masyarakat suku Saluan di Kabupaten Tojo Una- 
Una melaksanakan tradisi mongkanyang kompong, ritual adat tujuh bulanan pra kelahiran dan memanfaatkan berbagai spesies tumbuhan dalam uapacara kelahiran bayi (Purwanti et al. 2017). Masyarakat Desa Banmati, Sukoharjo menggunakan enam jenis tumbuhan dalam ritual adat pra kelahiran bayi yaitu mawar (Rosa sp.), melati (Jasminum sambac), dan kenanga (Cananga odorata), dan kunir (Curcuma longa, Padi (Oryza sativa), Kelapa (Cocos nucifera) (Syaffa et al. 2017).

\section{Aspek Sosial Budaya Dalam Tradisi Sengkineh}

Tradisi Sengkineh merupakan tradisi tujuh bulanan sejak kehamilan khas pesisir pantai di Kecamatan Keruak Kabupaten Lombok Timur. Menurut hasil wawancara pada sejumlah responden di wilayah pesisir pantai Kecamatan Keruak, tradisi Sengkineh dijalankan oleh tiga suku yang termasuk keturunan dari nenek moyang asal Selawesi yaitu Suku Mandar, Suku Bugis dan Suku Bajo. Tujuan tradisi Sengkineh untuk menyambut kelahiran bayi yang ada di dalam kandungan dan sebagai sugesti yang memberikan ketenangan bagi ibu hamil. Berikut ini adalah ritual tradisi Sengkineh yang memiliki nilai sosial budaya (Gambar 5).
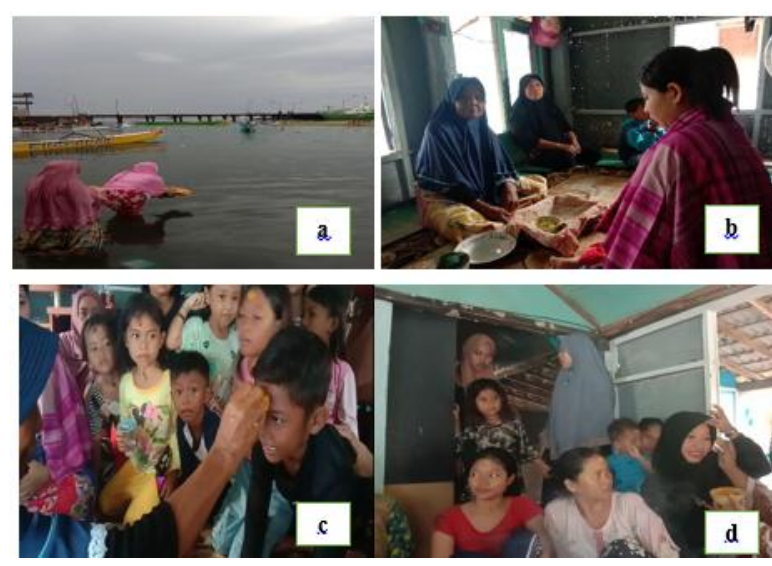

Gambar 5. Dokumentasi ritual Sengkineh yang memiliki nilai sosial budaya. Keterangan: (a) Pembuangan bala' ke laut, (b) Ritual sebelum melakukan bantang dan sembe', (c) Sembe', Bantang.

Gambar 5 merupakan ritual Sengkineh yang memiliki nilai sosial budaya. Ritual tersebut adalah ritual bantang dan sembe' yang merupakan tahap akhir ritual dalam tradisi Sengkineh. Bantang dan sembe' diartikan sebagai tanda sudah mengikuti ritual. Bantang dan sembe' hanya digunakan untuk ibu hamil yang disengkineh dan untuk tamu undangan yang hadir dalam tradisi Sengkineh. Ritual bantang dan sembe' memiliki nilai solidaritas yaitu rasa kebersamaan (kekompakkan) masyarakat dalam mengikuti ritual bantang dan sembe', memiliki rasa hormat atau toleransi terhadap sesama karena para tamu undangan yang hadir tidak hanya dari kalangan Suku Mandar, Suku Bugis, dan Suku Bajo akan tetapi dari semua kalangan. Selain itu, nilai yang ada dalam ritual bantang dan sembe' adalah nilai kerjasama antara satu dengan yang lain.

Pada ritual bantang dan sembe' juga memiliki nilai religius yang merupakan nilai kerohanian yang bersumber dari kepercayaan manusia. Menurut sanro (dukun) dan masyarakat lokal yang ada di wilayah pesisir pantai Kecamatan Keruak. Bantang dan sembe' diyakini sebagai pemberi keselataman, kesehatan bagi ibu yang disengkineh dan semua para tamu undangan yang telah hadir dalam ritual Sengkineh. Ritual bantang dan sembe' menggunakan jenis-jenis tumbuhan sebagai bahan penting dalam ritual Sengkineh yang merupakan pengetahuan dari nenek moyang. Bahan-bahan tersebut yakni beras (Oryza sativa), kunyit (Curcuma longa), sirih (Piper betle), dan pinang (Areca catechu). Bantang dan sembe' diartikan sebagai tanda sudah mengikuti ritual.

Pengetahuan sebagian masyarakat mengenai tumbuh-tumbuhan yang digunakan didapatkan dari nenek moyang terdahulu. Kurang lebih sejak tahun 1918 yang silam masyarakat Suku Bugis, Suku Bajo menempati Desa Tanjung luar, dengan pusat pemerintahannya di Dusun Kampung Tengah, pada saat itu masyarakat Desa Tanjung Luar belum memiliki pemerintahan yang definitif. Masa pemerintahan tersebut masih dipimpin oleh seororang kapitah (ketua adat) (Badan Pusat Statistik, 2020). Tradisi adalah kesamaan benda material dan gagasan yang berasal dari masa lalu namun masih ada hingga kini dan belum dihancurkan atau dirusak. Namun demikian tradisi yang terjadi berulang-ulang bukanlah dilakukan secara kebetulan atau disengaja. Dari pemahaman tersebut maka apapun yang dilakukan oleh manusia secara turun temurun dari setiap aspek kehidupannya yang merupakan upaya untuk meringankan hidup manusia dapat dikatakan sebagai "tradisi" yang berarti bahwa hal tersebut 
adalah menjadi bagian dari kebudayaan (Sztompka, 2007).

\section{Upaya Konservasi Tumbuhan yang Digunakan dalam Tradisi Sengkineh}

Pemahaman masyarakat lokal dalam penggunaan sumber daya alam secara bijak dan menyadari bahwa manusia merupakan bagian dari spektrum alam sehingga harus menjaga kelestarian dan konsep kesadaran ekologi yang harus dianut (Anshoriy \& Sudarsono, 2008). Penggunaan tumbuh-tumbuhan dalam tradisi Sengkineh sesungguhnya bertujuan untuk menanamkan nilai pelestarian alam pada jiwa setiap umat. Makna konservasi yang sebenarnya adalah pemanfaatan yang optimal untuk kesejahteraan masyarakat secara yang berkelanjutan (Pusat Pengkajian Strategi Kehutanan, 2012). Dengan nilai tersebut akan tumbuh suatu upaya untuk memelihara alam secara sungguh-sungguh dan kesejahteraan alam. Pada zaman modern ini banyak masyarakat yang tidak memperdulikan pentingnya konservasi tumbuhan guna melestarikan keberadaan sumber daya hayati.

Masyarakat wilayah pesisir pantai kecamatan Keruak dapat dikatakan masih mempertahankan kelestarian lingkungan mereka dengan menanam kembali beberapa jenis tanaman seperti Cocos nucifera, Curcuma longa, Capsicum annuum, di pekarangan rumah untuk berbagai keperluan. Beberapa responden mengatakan bahwa Cocos nucifera adalah pohon dengan beragam manfaat karena semua organ tumbuhannya dapat dimanfaatkan khususnya buah kelapa yang sangat berperan penting untuk pembuatan minyak wangi khas ritual yang wajib ada dalam ritual Sengkineh.

Ketersediaan minyak wangi khas ritual masih sangat minim karena tidak banyak warga yang memiliki keterampilan untuk membuat minyak kelapa. Minyak kelapa mutlak diperlukan dalam pembuatan minyak wangi khas ritual yang wajib ada dalam tradisi Sengkineh. Oleh karena itu, keterampilan masyarakat dalam pembuatan minyak kelapa harus dilestarikan. Pada wilayah pesisir pantai Kecamatan Keruak, upaya konservasi tumbuhan terbilang belum dilakukan dengan optimal karena masyarakat kebanyakan membeli di pasar. Jenis tumbuhan yang ditanam di pekarangan rumah hanya beberapa saja seperti kalapa Cocos nucifera, kunyit Curcuma longa, Pisang Musa paradisiaca, bawang merah Allium cepa, selain itu, lebih memilih membeli dipasar. Namun ada sebagian masyarakat yang memiliki lahan luas seperti sawah dan kebun dengan jenis tumbuhan yang ditanam seperti Oryza sativa, Nicotiana tabacum, dan Cocos nucifera. Selain itu, terdapat aturan-aturan terkait lingkungan seperti larangan menebang pohon sembarangan, larangan membuang sampah sembarangan, dan larangan membuang puting rokok di area kebun. Hal tersebut dikarenakan untuk menjaga kelestarian ekosistem lingkungan, dan sebagai upaya pemeliharaan lingkungan agar tetap terjaga.

Menurut Mumpuni et al. (2015), upaya konservasi sangat penting bagi keberlangsungan sumber daya hayati. Karena dalam ritual adat selalu memanfaatkan tumbuhan, maka kegiatan konservasi perlu terus dilakukan untuk menghindarkan tumbuhan dari risiko kepunahan. Upaya konservasi tumbuhan penunjang ritual/upacara dapat dilakukan oleh masyarakat dengan melakukan penanaman tumbuhan di wilayah sakral serta budidaya tumbuhan di pekarangan rumah masyarakat (Putri et al . 2015)

\section{Kesimpulan}

Spesies tumbuhan yang tergolong dalam 12 famili dan 17 genus digunakan dalam tradisi Sengkineh adat pesisir pantai di Kecamatan Keruak Kabupaten Lombok Timur. Tumbuhan yang paling banyak dimanfaatkan dalam tradisi Sengkineh dikelompokkan menjadi lima kategori tertinggi berdasarkan perhitungan Index of Cultural Significance (ICS) yaitu, Cocos nucifera sebesar 80, Piper betle sebesar 70, Musa paridisiaca "kepok" sebesar 70, Oryza sativa sebesar 56, dan Curcuma longa sebesar 44. Aspek sosial budaya yang terkandung dalam tradisi Sengkineh adalah solidaritas, toleransi, kerjasama antara satu dengan yang lain dan memiliki nilai religius yang merupakan nilai kerohanian yang bersumber dari kepercayaan manusia. Selain itu aspek sosial budaya yang terkandung dalam tradisi Sengkineh ialah dapat mempererat silaturahmi antar sanak, keluarga dan tetangga.

\section{Ucapan terima kasih}

Ucapan terima kasih disampaikan kepada semua pihak yang telah memberikan izin dalam 
pengambilan sampel selama penelitian. Kepada Universitas Mataram atas segala fasilitas yang diberikan sehingga penelitian berjalan lancar. Kepada narasumber dan tokoh masyarakat di Desa Ketapang Raya dan Tanjung Luar terima kasih atas kerjasama yang baik selama penelitian.

\section{References}

Anshoriy, N. \& Sudarsono (2008). Kearifan Lingkungan dalam Perspektif Budaya Jawa. Jakarta: Yayasan Obor Indonesia.

Astuti, NP (2009). Sifat Organoleptik Tempe Kedelai yang di Bungkus Plastik, Daun Pisang dan Daun Jati. Karya Tulis Ilmiah, Program Studi Gizi Diploma III Fakultas Ilmu Kesehatan: Universitas Muhammadiyah Surakarta, http://etd.eprints.ums.ac.id/5714/1/J diakses pada tanggal 8 Desember 2020.

Badan Pusat Statistik (BPS). (2020). Kecamatan Keruak dalam Angka 2020.

Hasanuddin, R. (2018). Kajian Etnobotani (Upacara Adat Suku Aceh Di Provinsi Aceh). Aceh: Jurnal Biotik, 6 (1), 53-38.

Hasanah, A. (2016). Nilai-Nilai Karakter Sunda (Internalisasi Nilai-Nilai Karakter Sunda di Sekolah), (Yogyakarta: Deepublish).

Hoffman, B. \& Gallaher, T., (2007). Importance Indices in Ethnobotany, A Journal of Plants, People And Applied Research.

Irsyad, M.N., Jumari \& Murningsih (2013). Studi Etnobotani Masyarakat Desa Sukolilo Kawasan Pegunungan Kendeng Pati Jawa Tengah, Bioma, (15): 27-34.

Jayusman (2014), Mengenal Pohon Kemenyan (Styrax spp.) Jenis dengan Spektrum Pemanfaatan Luas yang Belum Dioptimalkan. Bogor: IPB Press.

Liina, A.S., H.A Fauziah \& Nurmiyati (2017). Studi Etnobotani Tumbuhan Upacara Ritual Adat Kelahiran di Desa Banmati, Kecamatan Tawangsari, Kabupaten
Sukoharjo, BIOSFER, J.Bio., \& Pend.Bio, 2(2), 24-28.

Markhomah, AF. (2019). Makna Agama Dalam Ritual Sajen Pada Tradisi Pernikahan di Desa Blengorkulon Kecamatan Ambal Kabupaten Kebumen, Skripsi, Program Studi Agama, Fakultas Ushuluddin Adab dan Humaniora, Purwokerto.

Muhadjir (1996). Metodologi Penelitian Kualitatif, Rake Sarasin, Yogyakarta.

Mumpuni, K.E., Herawati Susilo \& Fatchur Rohman (2015). Peran Masyarakat dalam Upaya Konservasi. Seminar Nasional XII Pendidikan Biologi FKIP UNS.

Purwanti, Miswan \& Pitopang R. (2017). Studi Etnobotani Pada Proses Ritual Adat Masyarakat Suku Saluan Di Desa Pasokan Kabupaten Tojo Una-Una. Biocelebes, Juni 2017, Hlm. 46-60 Issn-P: 1978-6417

Pusat Pengkajian Strategis Kehutanan (2012). Hasil Kajian Strategis Kehutanan 2011, Jakarta: Yayasan Sarana Wana Jaya, (Online), (http://puskashut.com). 23/11/2020.

Putri, Supriatna J. \& Walujo, EB. (2015). Etnobotani Tumbuhan Penunjang Ritual/Adat Di Pulau Serangan, Bali. Prosiding Seminar Nasional Prodi Biologi F. MIPA UNHI.

Rini, F. Yulian \& D. Akbarin (2017). Pemanfaatan Daun Sebagai Pembungkus Makanan Tradisional oleh Masyarakat Bangka (Studi Kasus di Kecamatan Merawang). Fakultas Pertanian dan Perikanan Universitas Bangka Belitung.

Rahimah \& Hasanuddin, Djufri (2018). Kajian Etnobotani Upacara Adat Suku Aceh Di Provinsi Aceh. Jurnal Biotik, 6(1). ISSN: 2337-9812, Ed. April 2018, Hal. 53-58

Rongiyati, S. (2011). Hak Kekayaan Intelektual Atas Pengetahuan Tradisional, Negara Hukum. 2(2):214-238. 
Sartini (2009). Mutiara Keariafan Lokal Nusantara, Yogyakarta: Kepel.

Solikhin, M. (2010). Ritual dan Tradisi Islam Jawa, Anggota IKAPI: Yogyakarta.

Sugiyono (2010). Metode Penelitian Pendidikan, Alfabeta, Bandung.

Syaffa A., Liina A., Fauziah HA. \& Nurmiyati (2017). Studi Etnobotani Tumbuhan Upacara Ritual Adat Kelahiran di Desa Banmati, Kecamatan Tawangsari, Kabupaten Sukoharjo . BIOSFER, J.Bio. \& Pend.Bio. 2(2), Desember 2017

Sztompka, P., (2007). Sosiologi perubahan sosial, Jakarta: Prenada Media Grup. 